\title{
EFFECT OF MIXING RATIO AND PLANTING YEARS ON THE MICRO STRUCTURE OF SOFT ROCK AND SAND COMPOUND SOIL: A SCANNING ELECTRON MICROSCOPE STUDY
}

\author{
LI, J. ${ }^{1,2,3,4}$ - HAN, J. C. ${ }^{1,2,3,4}$ - WANG, Y. K. ${ }^{1,2,3,4}$ - GE, L. ${ }^{1,2,3,4}$ - TIAN, C. ${ }^{1,2,3,4}-$ SHI, C. D. ${ }^{1,2,3,4}-$ \\ WANG, H. Y. $.^{1,2,3,4^{*}}-$ GUO, H. ${ }^{1,2,3,4}$
}

${ }^{1}$ Shaanxi Provincial Land Engineering Construction Group Co. Ltd. /Shaanxi key Laboratory of Land Consolidation, $710075 \mathrm{Xi}$ 'an, China

${ }^{2}$ Institute of Land Engineering Technology in Shaanxi Province Co. Ltd., 710075 Xi'an, China

${ }^{3}$ Key Laboratory of Degraded and Unused Land Consolidation Engineering Ministry of Nature and Resources PRC, 710075 Xi'an, China

${ }^{4}$ Shaanxi Provincial Land Consolidation Engineering Technology Research Center710075

Xi'an, China

${ }^{*}$ Corresponding author

e-mail:2644816206@qq.com; phone: +86-029-8662-5017; fax: +86-029-8662-5017

(Received $1^{\text {st }}$ Mar 2019; accepted 21 ${ }^{\text {st }}$ May 2019)

\begin{abstract}
To illustrate the internal micro-mechanism of macro-properties for soft rock and sand compound soil. The compound soil with the mixing ratios of soft rock to sand 1:1, 1:2 and 1:5 which planted in six years, and the ratio of 1:2 planted in one, five and six years were characterized by scanning electron microscope (SEM) to observe the micro structures. The results showed that (1) in the 1:1 compound soil, the silt particles and sandy particles accounted for about $62.5 \%$ and $37.5 \%$. Compared with sand, the content of silt particles in 1:1 compound soil increased by about $26 \%$, while the sandy particles decreased by about $26 \%$. (2) The coarse sandy particles $(0.25 \sim 1 \mathrm{~mm})$ decreased from $9.2 \%$ for 1:2 compound soil planted in one year to $2.0 \%$ that planted in six years. In contrast, the fine silt particles (0 0.01 mm) increased from $20.7 \%$ to $32.6 \%$. With increasing wheat planting years, soil particles of compound soil became finer, which was consistent with the situation that adding soft rock into sand. (3) After six-year wheat planting, the number of soil aggregate for 1:5 and 1:1 compound soil were 1.0 and 2.5. While the number of soil aggregate was 2.0 for 1:2 compound soil after one-year wheat planting, which increased to 8.0 after six-year wheat planting. With the increase of soft rock into sand or wheat planting years, the number of soil aggregate increased also, thus the soil quality was greatly improved.
\end{abstract}

Keywords: micro-mechanism, SEM, soil particles, soil aggregate, long-term planting

\section{Introduction}

Soft rock refers to the interbed rock which is composed of thick sandstone, sand shale and argillaceous sandstone of Paleozoic Permian, Mesozoic Triassic, Jurassic and Cretaceous (Bazhenov et al., 1993; Martin et al., 1999; Zhang et al., 2009a). Soft rock is as hard as stone without water, while as soft as mud when it meets water. Water and wind erosion is poorly tolerable for soft rock, which can lead to a large amount of soil loss and 
thus a disaster for local people (Yang et al., 2014). Soft rock is mainly distributed at the junction of Shanxi, Shaanxi and Inner Mongolia where partly overlaps with Mu Us Sandy Land. Soft rock and sand presents interphase distribution there (Zhang et al., 2009b). Sandy soil there is loose and has no structure which results in serious leakage of water and fertilizer and soil erosion problem. It has been proposed that soft rock can be blended with sand to form compound soil, which compensates the shortcomings in the structure of sandy soil that can be further used for planting (Wang et al., 2013). Compared to sand, the texture of compound soil has been improved (Zhu et al., 2017) and the water and fertilizer holding capacity has been significantly increased (Han et al., 2012; Wang et al., 2014, 2016).

The study of soil microstructure is helpful to the further understanding of soil properties and its intrinsic mechanism. Currently, scanning electron microscopy (SEM) is usually applied for studying the microstructure of soil (Montes et al., 2005; Sayen et al., 2009; Romero, 2013; Lin and Cerato, 2014; Jiang et al., 2014;). Chang et al. (2015) directly observed the morphology of sand, clay, and Red Yellow soil treated by Xanthan gum with SEM, showing the connection mechanism of Xanthan gum with soils of different particle sizes. SEM and energy dispersive spectrometer (EDS) can be jointly used for semi-quantitative analysis of matter elements. Ramamurthy and Kannan (2009) studied the effects of atmospheric pollution by analyzing heavy metals in soil and plants collected from an industrial area with SEM-EDS method. Through this, a perceptible variation in the trace element concentration of samples in different seasons can be found. For the study of soft rock, Li et al. (2016) used SEM to observe the microstructure of soft rock geopolymer materials and discussed the influences of fly ash content and curing age on the mechanical properties and microstructure of soft rock geopolymer material. However, the microstructure of soft rock and sand compound soil is still unclear. The study of the microstructure of compound soil is also helpful for improving the macro properties of compound soil by laying the theoretical and technical foundation in the micro level, which provides efficient support for the resource utilization of soft rock.

In this work, soft rock, sand and compound soil were observed by SEM to study the effect of mixing ratio and wheat planting year on the soil microstructure. Compound soil with the mixing ratios of soft rock to sand 1:1, 1:2, and 1:5 which planted in six years, and the ratio was 1:2 planted in one year, five years, and six years were characterized by scanning electron microscope (SEM) to observe the micro structures. Microstructures of soil with different treatments were qualitatively compared. Statistical analysis of the micro images showed the variation trends of particle size and aggregate number, etc., as a function of mixing ratio and wheat planting ages. The application of SEM can not only determine the microstructural changes observed in the soil, but also simultaneously determine the main components of the cement material in the process of sand becoming soil, and compare the particle size distribution information measured by laser particle size analyzer to reveal relationship between the microscopic and Macroscopic composite soil. 


\section{Materials and methods}

\section{Materials}

Soft rock and sand were collected from Yuyang District, Yulin City $\left(108.58^{\circ} \mathrm{E}\right.$ to $110.24^{\circ} \mathrm{E}, 37.49^{\circ} \mathrm{N}$ to $38.58^{\circ} \mathrm{N}$ ). The altitude ranges from 1000 to $1600 \mathrm{~m}$. The area is in medium-temperate arid climate zone. All the experimental fields were artificially sown. The tested wheat variety was Xiaoyan 22, with an average 1000-grain weight of $38 \mathrm{~g}$ and a wheat germination rate of $90.1 \%$. The wheat yield is $150 \mathrm{~kg} / \mathrm{hm}^{2}$ and the line spacing is $20 \mathrm{~cm}$. Before wheat planting, apply the base fertilizer (diammonium phosphate $300 \mathrm{~kg} / \mathrm{hm}^{2}$, urea $150 \mathrm{~kg} / \mathrm{hm}^{2}$ ). Winter irrigation treatment of urea 150 $225 \mathrm{Kg} / \mathrm{hm}^{2}$, spring application of urea $150 \sim 225 \mathrm{~kg} / \mathrm{hm}^{2}$, irrigation 3 times, winter irrigation 1 time, spring irrigation 1 time, filling period 1 time, chemical weeding 1 time in spring, a spray three defense after heading.In addition, soft rock and sand compound soil after six-year wheat planting with three proportions (1:1, 1:2, 1:5, respectively) and compound soil with ratio of 1:2 after one-year, five-year and six-year crop cultivation were collected respectively. Sample information was given in Table 1.

Table 1. Details of soil samples

\begin{tabular}{c|c|c}
\hline Sample & Mixing Ratio of Soft Rock to Sand & Wheat Planting Year \\
\hline Soft Rock & $1: 1$ & 6 \\
Compound Soil & $1: 2$ & 1 \\
Compound Soil & $1: 2$ & 5 \\
Compound Soil & $1: 2$ & 6 \\
Compound Soil & $1: 5$ & 6 \\
Compound Soil & & \\
Sand & & \\
\hline
\end{tabular}

\section{Methods}

The microscopic structure of collected soil samples was characterized by FEI Q45 SEM. Soil samples with a good flat surface were prepared on the sample stage, which were observed at the voltage of $25 \mathrm{kV}$. The magnification times gradually increased and photographs were taken at magnification times of 100, 500, 1000 and 2000, respectively. The obtained surface microstructure images of soil samples were analyzed and processed. The particle size was measured by the Nano Measure software. Specifically, the scale on the picture was used as a reference, and then lines were crossed on the maximum diameter of all the soil particles, including the attached clay and silty particles, to obtain the particle size. The measurement results were output and the number of particles classified by size into several levels was counted. Through the picture, the number of aggregates and other sample information were also obtained. The soil particle size composition, the number of aggregates, etc., were plotted as a function of mixing ratio of compound soil or wheat planting year. 
According to the X-ray diffraction method, clay mineral samples with particle size less than $10 \mu \mathrm{m}$ and less than $2 \mu \mathrm{m}$ in 1:2 compound soil with wheat planting years of 1 year, 5 years and 6 years were extracted according to the Stokes settlement theorem. A clay mineral sample having a particle diameter of less than $10 \mu \mathrm{m}$ is used for determining the total relative content of clay minerals; a clay mineral sample having a particle diameter of less than $2 \mu \mathrm{m}$ is used to determine the relative content of each clay mineral.

\section{Results and Discussion}

\section{Micro-morphology of compound soil}

\section{Microstructure of compound soil with different mixing ratios}

The texture of soft rock and sand compound soil with different proportions has been studied by laser particle size analyzer (Zhu et al., 2017). The volume of soil particles with different grain sizes was measured by laser, so as to obtain the percentage of each grain size. Compared with this indirect measurement method, it was more intuitive to measure the particle size through micro-image obtained by SEM. In addition, the morphology of the soil particle surface and the interface between particles can be seen.

Fig. 1 showed the SEM images of compound soil with different proportions after wheat planting for six years. Fig. 1(a-d), Fig. 1(e-h), and Fig. 1(i-l) respectively illustrated the composite soils with ratios of 1:1, 1:2, and 1:5. The magnification times for images from top to bottom were 100, 500, 1000, and 2000, respectively. From the images of lower magnification times (100 and 500 times), it can be seen that there was more cementing matter between soil particles under the ratio of 1:1. As the content of sand increased, the particles became dispersed and the cementation material became less. In the images with higher magnification times of 1000 and 2000 times, it showed that there were more matter attached on the surface of soil particles under the ratio of 1:1 and 1:2 than that with the ratio of 1:5. With the increasing content of soft rock, the particles mostly presented face contact to each other and more cementing materials bonded them together, maintaining certain content of pores and good agglomeration property.

\section{Microstructure of compound soil with different wheat planting ages}

Fig. 2 showed the images of compound soil with the ratio of 1:2 which planted in different ages under SEM. Fig. 2(a-d), Fig. 2(e-h) and Fig. 2(i-l) were the images of compound soil with one-year, five -year and six-year wheat planting ages, respectively. The magnification times from top to bottom were 100, 500, 1000 and 2000 times, respectively. In lower magnification images of 500 and 1000 times, it can be seen that the surface of soil particles after one-year planting was relatively smooth, while with the increasing wheat planting years, more attachments appeared on the surface of soil particles. Higher magnification images (1000 and 2000 times) indicated that the soils were relatively dispersive after one year wheat planting. The inter-particle boundaries 
were clear and cementing matter was less. In contrast, the compound soil planted in five and six years presented closer connection, smaller pores and richer intergranular cementation. This was due to the increase of soil organic matter content during several years of crop cultivation, such as irrigation and fertilization. In addition, root exudates, soil biological activities and their products, and humus etc. can make the soil agglomeration better, so that the soil structure improved remarkably.

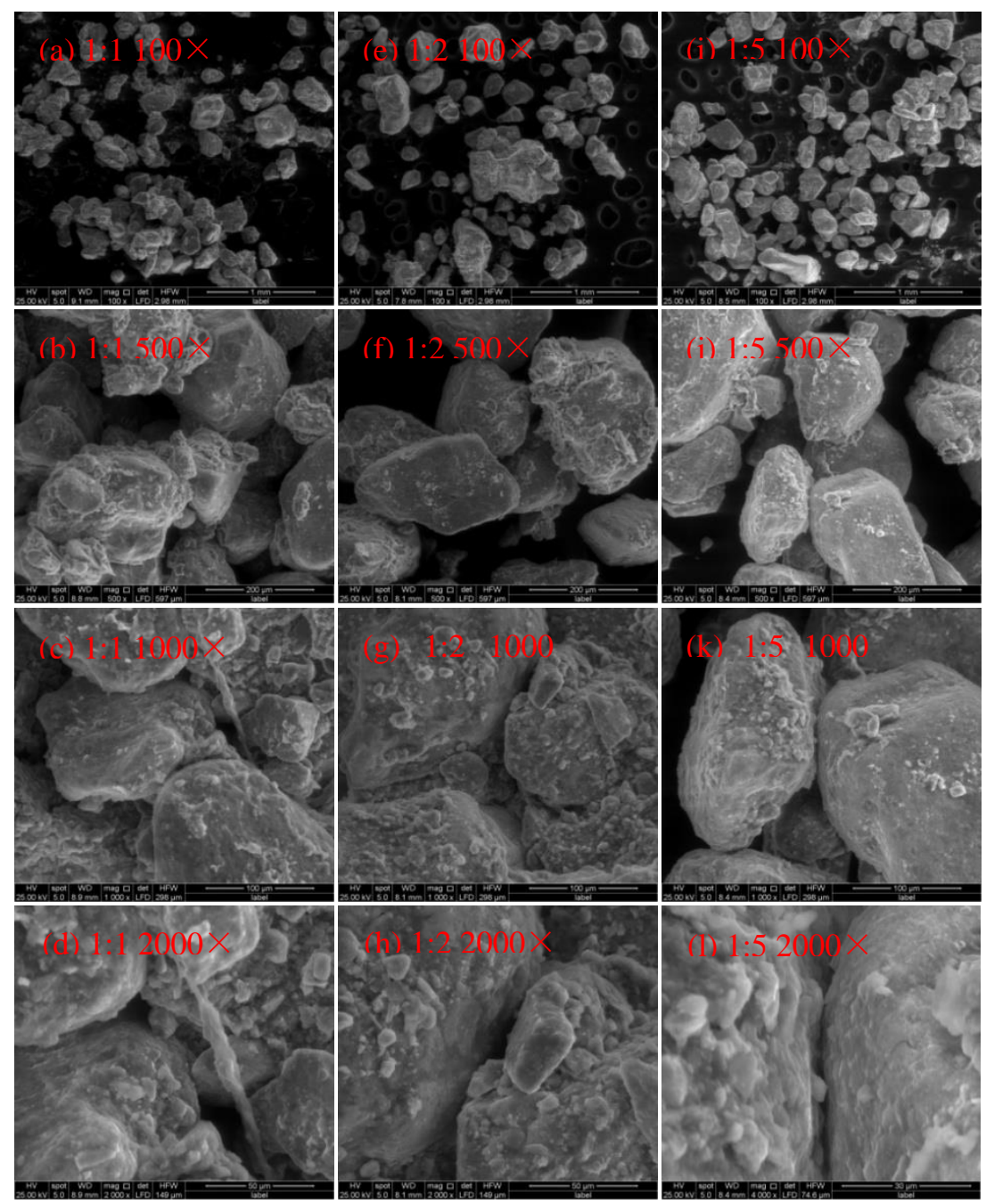

Figure 1. SEM images of soft rock and sand compound soil with different ratios after six-year wheat planting. The ratios of soft rock to sand were 1:1, 1:2, and 1:5 for $(a-d),(e-h)$, and (i-l), respectively. The magnification times were 100,500, 1000, and 2000 respectively for (a, e, and $i),(b, f$, and $j),(c, g$, and $k)$, and $(d, h$, and $l)$

By section analysis of compound soil aggregates, backscattered electron imaging and $\mathrm{X}$-ray energy spectrometer analysis showed that the elemental composition of cemented materials in compound soil was mostly $\mathrm{O}, \mathrm{Mg}, \mathrm{Al}, \mathrm{Si}, \mathrm{K}, \mathrm{Ca}, \mathrm{Fe}$. In combination with Oades' research on soils with low organic matter content and high clay mineral and iron-aluminum oxide content, it is found that the formation of agglomerates mainly 
depends on the cohesive force of cosmids and the cementation of iron-aluminum oxides. It is believed that the cemented material in the compound soil is mainly clay mineral and is closely packed between the bone particles.

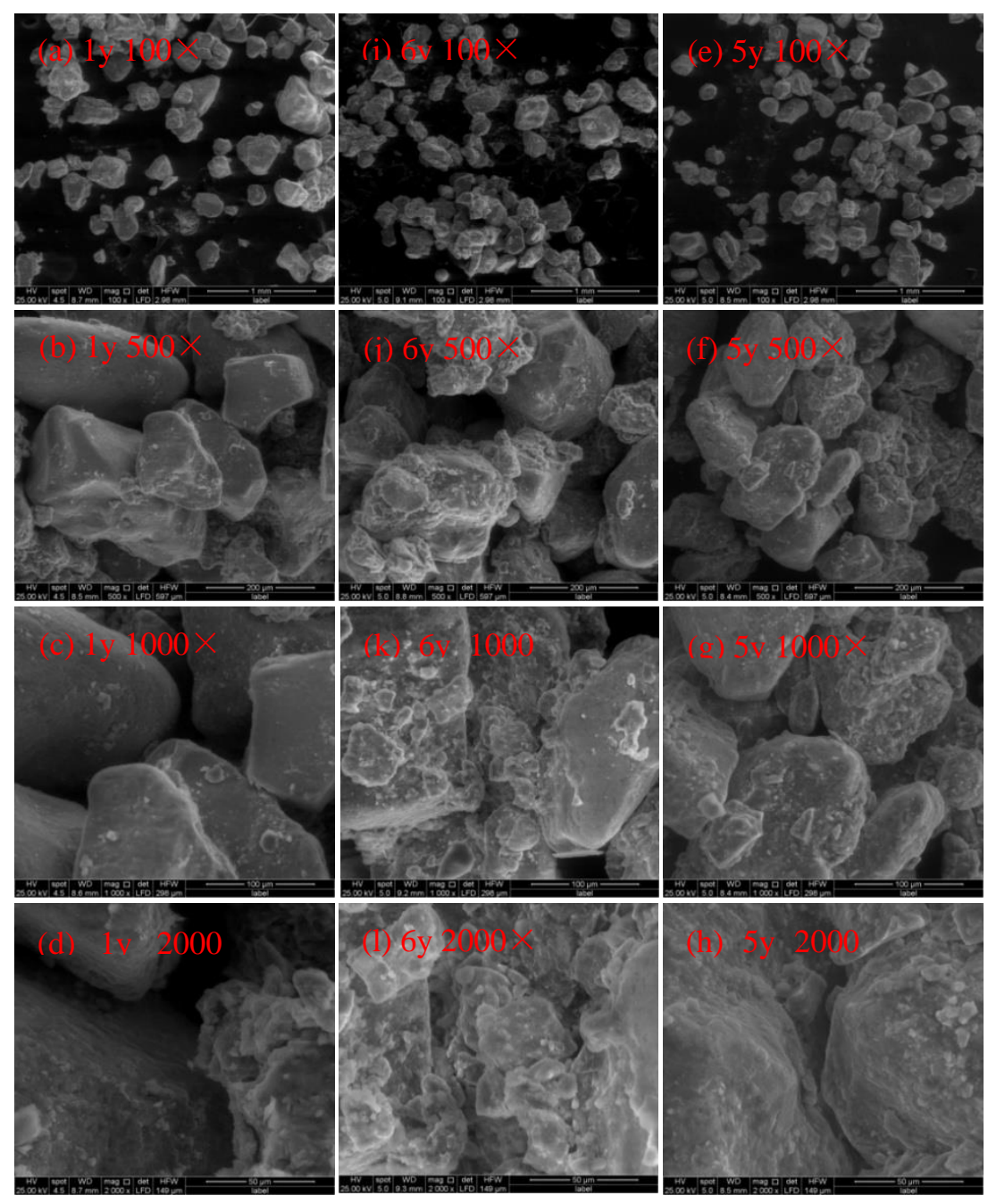

Figure 2. SEM images of soft rock and sand compound soil with different wheat planting years.

The ratio of soft rock to sand was 1:2, and the wheat planting years were one year, five years, and six years for $(a-d),(e-h)$, and $(i-l)$, respectively. The magnification times were 100, 500, 1000 , and 2000 respectively for ( $a, e$, and $i),(b, f$, and $j),(c, g$, and $k)$, and $(d, h$, and $l)$

According to the XRD analysis, the content of clay minerals in the compound soil increased with the increasing wheat planting years, shown as Table 2 and increased from $18.2 \%$ after wheat planting in 1 year to $22.4 \%$ after 6 years wheat planting, which greatly improved the cementing property of the compound soil. There is a significant difference between the compound soil of 5 years and 6 years and the initial stage of compounding. The clay minerals in the compound soil were mainly water-sensitive illite-montmorillonite mixed layer, which accounts for $49 \sim 51 \%$ of clay minerals, and the proportion of different kinds of clay minerals was similar. 
Table 2. Content analysis of cementing materials in compound soil and aeolian sand soil

\begin{tabular}{c|c|c|c|c|c}
\hline \multirow{2}{*}{ Years of planting } & \multirow{2}{*}{ Clay mineral content (\%) } & \multicolumn{4}{|c}{ Relative content of clay minerals (\%) } \\
\cline { 3 - 6 } & & I/S & It & Kao & C \\
\hline 1 & 18.2 & 49 & 26 & 12 & 13 \\
5 & 21.9 & 51 & 25 & 13 & 11 \\
6 & 22.4 & 51 & 25 & 11 & 13 \\
\hline
\end{tabular}

I/S: Illite-montmorillonite mixed layer; It: Illite

\section{Particle gradation of compound soil}

According to the soil texture classification of United States Department of Agriculture (USDA) (Drzymala, 2000), the range of sandy particle size 0.05 to $1 \mathrm{~mm}$, while in this paper, the sandy particle was divided into fine sandy particles $(0.05 \sim 0.25 \mathrm{~mm})$ and coarse sandy particles $(0.25 \sim 1 \mathrm{~mm})$. The particles whose size ranged from 0.002 to $0.05 \mathrm{~mm}$ were called silty particles and that smaller than $0.002 \mathrm{~mm}$ were called clay particles. Since the resolution capacity is not enough for the Nano Measure software to distinguish the clay particles, the 0 to $0.05 \mathrm{~mm}$ particles were all denoted as silty particles in this work, in which $0 \sim 0.01 \mathrm{~mm}$ and $0.01 \sim 0.05 \mathrm{~mm}$ particles were denoted as fine and coarse silty particles, respectively.

\section{Particle gradation of compound soil with different mixing ratios}

As shown in Fig. 3, the content of sandy particles in sand was more than 63.5\%, and the content of fine silty particles $(0 \sim 0.01 \mathrm{~mm})$ was only $2.3 \%$. The content of sandy particles in soft rock was about $19.6 \%$, and the content of fine silty particles was up to $32.3 \%$. In addition, the content of coarse silty particles was also very high, about $48.1 \%$.

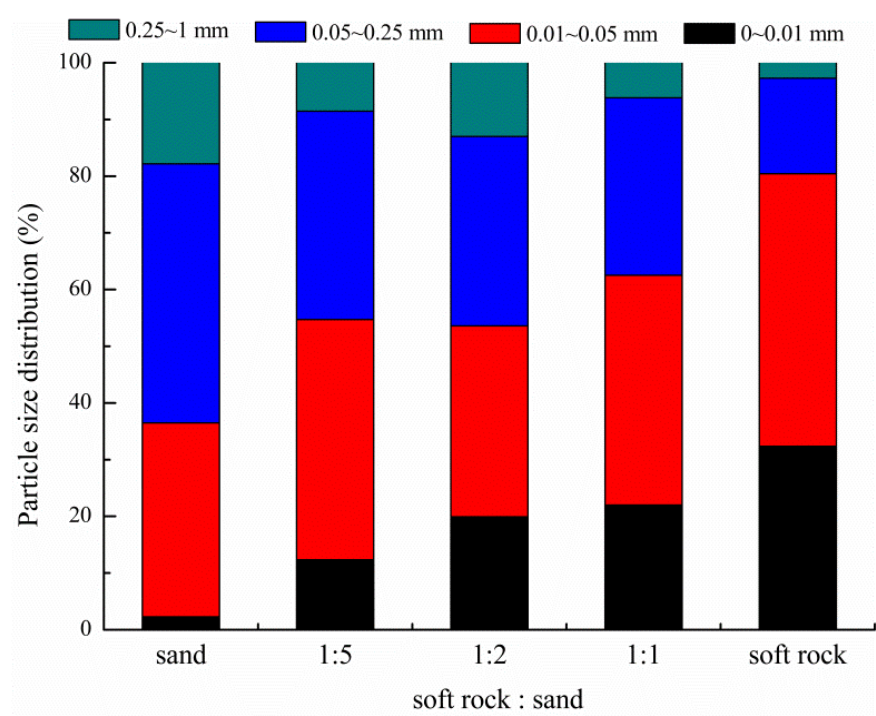

Figure 3. The particle size distribution of soft rock and sand compound soil with different mixing ratios after six-year wheat planting 
By comparison, the measurement results of particle size by SEM and laser particle size analyzer (Zhang et al., 2015) were basically the same. It indicated that the riched fine particles in soft rock made up for the lack of fine particles in sand. The content of sandy particles in compound soil with the ratio of $1: 1$ was about $37.5 \%$, in which about $6.2 \%$ was coarse sandy particles, and the content of silty particles was about $62.5 \%$, in which the fine silty particles was about $40.5 \%$. Compared with sand, the content of silty particles increased by about $26 \%$, and the content of sandy particles decreased by about $26 \%$. The particle size distribution of compound soil can be altered by adjusting the proportion of soft rock and sand. With the adding soft rock into sand, the percentage of coarse particles decreased while the fine particles increased. Furthermore, the trend was more obvious with the increasing proportion of soft rock in sand. The mixing of soft rock and sand not only significantly improved the soil texture but also increased the content of fine particles, which was beneficial to the formation of soil agglomeration and capillary pores, so as to enhance the water retention capacity of soil.

\section{Particle gradation of compound soil with different wheat planting ages}

Fig. 4 displayed the particle size distribution of compound soil with the ratio of 1:2 as a function of wheat planting year. It can be seen that the content of coarse sandy particles decreased with the increase of wheat planting period, from $9.2 \%$ for one-year tillage to $2.0 \%$ for six-year tillage.

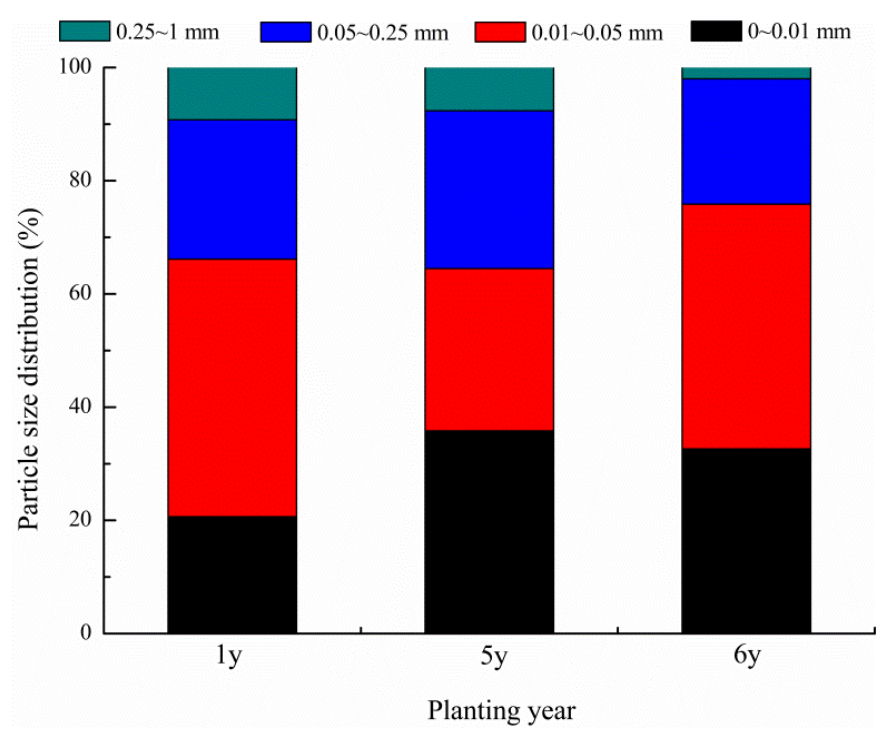

Figure 4. The particle size distribution of soft rock and sand compound soil (the ratio is 1:2) with different wheat planting years

Besides, the content of fine silty particles increased from $20.7 \%$ for one-year wheat planting to $32.6 \%$ for six-year wheat planting. With the increase of tillage time, the content of sandy particles decreased while silty particles increased, which was attributed to the comprehensive actions of tillage, irrigation, and activities of crop root, animal and 
microorganism. By comparing the particle size distribution of compound soil after five-year and one-year wheat planting, it can be found that with the increasing wheat planting years, the coarse sandy particles crushed into fine sandy or silty particles and coarse silty particles crushed into fine silty particles under the action of root and microorganisms. Thus, the content of coarse sandy and coarse silty grains decreased, while the content of fine sandy and fine silty grains increased. After six-year wheat planting, soil particles continued to become finer gradually, therefore, the content of coarse and fine sandy granules declined, and the content of coarse and fine silty particles increased, which was conducive to the rational distribution of soil particles, the formation of pore structure with good performance of ventilation, water permeability, fertilizer holding, etc. Thus, the land quality was improved.

\section{Aggregation characteristics of compound soil}

Fig. 5 was the mean number of coacervates in multiple images (the magnification times was 100) of compound soil after six-year wheat planting as a function of the mixing ratio. With the increase of soft rock in sand, the number of coacervates also increased, raging from 1 for the ratio of $1: 5$ to 2.5 for the ratio of 1:1. From the ratio of $1: 5$ to $1: 1$, the number of coacervates increased by $75.0 \%$ and $42.9 \%$, respectively.

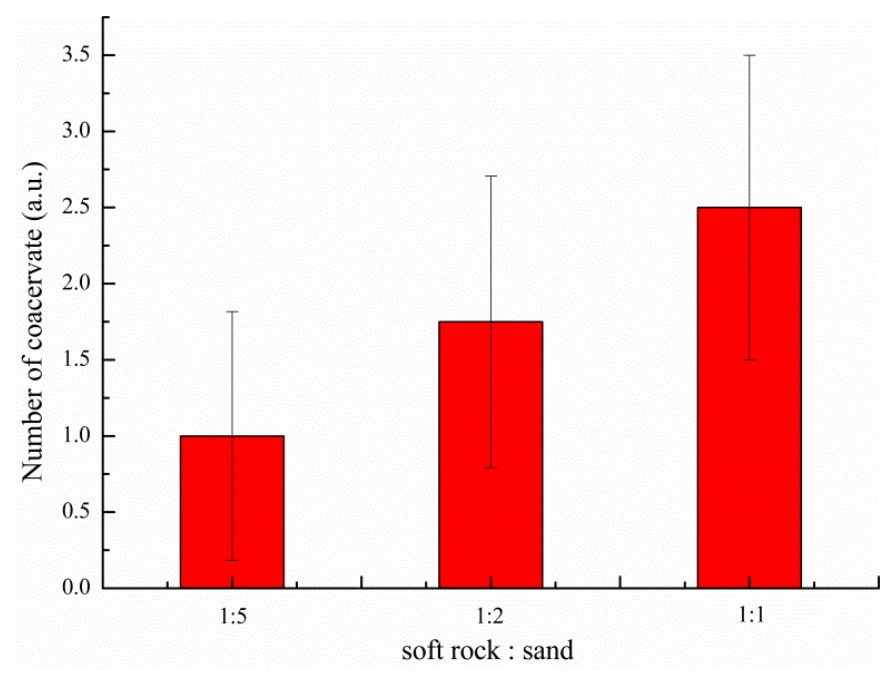

Figure 5. The number of coacervate of soft rock and sand compound soil with different ratios after six-year wheat planting

Fig. 6 was the mean number of coacervates in 100 times magnification of compound soil with ratio of $1: 2$, which plotted as a function of wheat planting year. With the increase of the wheat planting period, the number of coacervates increased too, varying from 2 for one-year wheat planting to 8 for the six-year wheat planting. Among three wheat planting, the increase in the number of coacervates was $100.0 \%$. In terms of the relationship between particle size and formation of aggregates, it was considered that the more the fine particles, the stronger the soil aggregation ability. Aggregation refers 
to the process of agglomeration of soil particles resulted from various forces. The main external forces included the effects of plant roots, fossorial animals, soil tillage, alternation of dry and wet, and alternation of freeze and thaw, etc. Section 3.2.1 indicated that after six years wheat planting, with the increasing proportion of soft rock in the compound soil, the content of sandy grains decreased while the silty grains increased. The finer particles would accelerate the formation of aggregates, which was consistent with the result shown in Fig. 5. It can be seen in section 3.2.2 that with the increasing wheat planting years, for the compound soil with the ratio of $1: 2$, the soil particles became finer, which was beneficial to the formation of aggregates.

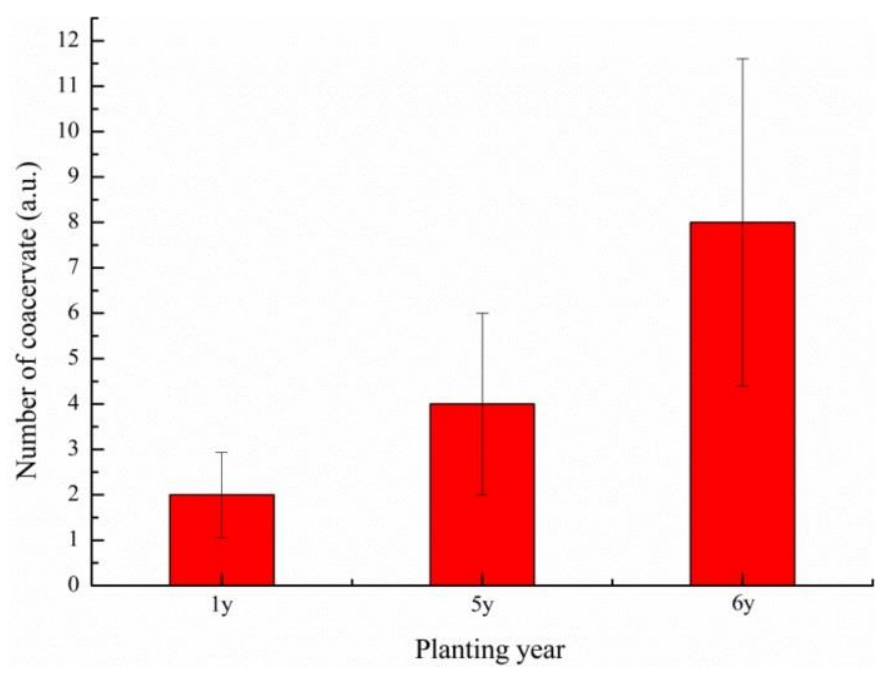

Figure 6. The number of coacervate of soft rock and sand compound soil (the ratio was 1:2) with different wheat planting years

In Fig. 6, the number of aggregates increased with the increasing wheat planting ages, resulting from the inserting, cutting, squeezing effect of plant roots and fossorial animal during the wheat planting period. In addition, the enwinding of mycelium to the soil particles played a role as forming power (Aspiras et al., 1971; Tisdall and Oades, 1980), and mycelial secretion played an important role of cementing soil particles (Martin et al., 1955). Timely and reasonable cultivation, intertillage, raking, repression and other measures with chopping, squeezing and other effects would also be conducive to the formation of aggregates.

\section{Conclusion}

The improvement effect of sandy soil properties by mixing soft rock and sand into compound soil was studied with the mono-factor analysis method under SEM. The samples were compound soil planted in six years with mixing ratio of 1:1, 1:2, 1:5, respectively, and compound soil planted in one, five and six years with the ratio of 1:2. The effect of mixing ratio and wheat planting ages on microstructure and properties of 
compound soil was analyzed. It was found that with the increasing amount of soft rock in compound soil, the soil particles became much more fine. The grain composition of sandy soil was significantly improved by adding of soft rock. The content of silty particles for compound soil planted in six years with the ratio of 1:1 increased by $26 \%$ compared to the sandy soil, and the sandy particles decreased by about $26 \%$. With the increase of wheat planting period, due to farming activities and activities of plant roots and soil microorganisms, etc., soil particles of compound soil continuously got finer, and the distribution of particle size became more reasonable. The content of coarse sandy particles decreased from $9.2 \%$ for one-year wheat planting to $2.0 \%$ for six-year wheat planting, while the content of fine silty particles increased from $20.7 \%$ to $32.6 \%$. With the increasing content of soft rock in compound soil or the wheat planting period, the number of soil aggregates increased, raging from 1 for 1:5 ratio to 2.5 for 1:1 ratio planted in six years, and from 2 for one-year wheat planting to 8 for six-year wheat planting whose ratio was 1:2. In conclusion, soil quality has been improved with the addition of soft rock or the increase of planting years. Finally, the analysis of microstructure for compound soil laid a good foundation for the study of the inherent mechanism of macroscopic performance.

Acknowledgements. Supported by the Fundamental Research Funds for the Central Universities, CHD (300102279503); The Fund Project of Shaanxi Key Laboratory of Land Consolidation (2018-JC18, 2019-JC08); Shaanxi Provincial Land Engineering Construction Group Ltd., internal research project (DJNY2019-12, DJNY2018-12).

\section{REFERENCES}

[1] Aspiras, R. B., Allen, O. N., Chesters, G., Harris, R. F. (1971): Chemical and Physical Stability of Microbially Stabilized Aggregates. - Soil Science Society of America Journal 35: 283.

[2] Bazhenov, M. L., Chauvin, A., Audibert, M., Levashova, N. M. (1993): Permian and Triassic paleomagnetism of the southwestern Tien Shan: timing and mode of tectonic rotations. - Earth \& Planetary Science Letters 118: 195-212.

[3] Chang, I., Im, J., Prasidhi, A. K., Cho, G. C. (2015): Effects of Xanthan gum biopolymer on soil strengthening. - Construction \& Building Materials 74: 65-72.

[4] Drzymala, S. (2000): Comparison of soil texture classification according to the new Polish Standard, PTG and international classifications [FAO and USDA]. - Acta Agrophysica 35: 49-53.

[5] Han, J., Xie, J., Zhang, Y. (2012): Potential role of feldspathic sandstone as a natural water retaining agent in Mu Us Sandy Land, Northwest China. - Chinese Geographical Science 22: 550-555.

[6] Jiang, M., Zhang, F., Hu, H., Cui, Y., Peng, J. (2014): Structural characterization of natural loess and remolded loess under triaxial tests. - Engineering Geology 181: 249-260.

[7] Li, C., Wang, L., Zhang, T., Yang, D., Song, L. (2016): Preparation of geopolymer materials by Pisha sandstone. - Journal of Building Materials 19: 373-378. 
[8] Lin, B., Cerato, A. B. (2014): Applications of SEM and ESEM in Microstructural Investigation of Shale-Weathered Expansive Soils along Swelling-Shrinkage Cycles. Engineering Geology 177: 66-74.

[9] Martin, J. P., Martin, W. P., Page, J. B., Raney, W. A., Ment, J. D. D. (1955): Soil Aggregation. - Advances in Agronomy 7: 1-37.

[10] Martin, M. W., Jorge, C. R., Constantino, M. M. (1999): Late Paleozoic to Early Jurassic tectonic development of the high Andean Principal Cordillera, El Indio Region, Chile (29-30 ${ }^{\circ}$ S). - Journal of South American Earth Sciences 12: 33-49.

[11] Montes-H, G., Geraud, Y., Duplay, J., Reuschlé, T. (2005): ESEM observations of compacted bentonite submitted to hydration/dehydration conditions. - Colloids \& Surfaces A Physicochemical \& Engineering Aspects 262: 14-22.

[12] Ramamurthy, N., Kannan, S. (2009): SEM-EDS analysis of soil and plant (Calotropis gigantea Linn) collected from an industrial village, Cuddalore DT, Tamil Nadu, India. Romanian Journal of Biophysics 19: 219-226.

[13] Romero, E. (2013): A microstructural insight into compacted clayey soils and their hydraulic properties. - Engineering Geology 165: 3-19.

[14] Sayen, S., Mallet, J., Guillon, E. (2009): Aging effect on the copper sorption on a vineyard soil: column studies and SEM-EDS analysis. - Journal of Colloid \& Interface Science 331: 47.

[15] Tisdall, J. M., Oades, J. M. (1980): The effect of crop rotation on aggregation in a red-brown earth. - Australian Journal of Soil Research 18: 423-433.

[16] Wang, N., Xie, J., Han, J. (2013): A Sand Control and Development Model in Sandy Land Based on Mixed Experiments of Arsenic Sandstone and Sand: A Case Study in $\mathrm{Mu}$ Us Sandy Land in China. - Chinese Geographical Science 23: 700-707.

[17] Wang, N., Xie, J., Han, J., Luo, L. (2014): A comprehensive framework on land-water resources development in Mu Us Sandy Land. - Land Use Policy 40: 69-73.

[18] Wang, H., Han, J., Tong, W., Cheng, J., Zhang, H. (2016): Analysis of water and nitrogen use efficiency for maize (Zea mays L.) grown on soft rock and sand compound soil. Journal of the Science of Food \& Agriculture. doi: 10.1002/jsfa.8075.

[19] Yang, F. S., Cao, M. M., Li, H. E., Wang, X. H., Bi, C. F. (2014): Ecological restoration and soil improvement performance of the seabuckthorn flexible dam in the Pisha Sandstone area of Northwestern China. - Solid Earth Discussions 6: 2803-2842.

[20] Zhang, K., Xu, M., Wang, Z. (2009a): Study on reforestation with seabuckthorn in the Pisha Sandstone area. - Journal of Hydro-environment Research 3: 77-84.

[21] Zhang, K., Xu, M., Wang, Z., Duan, X., Bi, C. (2009b): Ecological impacts of seabuckthorn in the Pisha Sandstone area. Advances in Water Resources and Hydraulic Engineering. - Springer Berlin Heidelberg. doi: 10.1007/978-3-540-89465-0_193.

[22] Zhang, L., Han, J., Wang, H., Ma, Z. (2015): Grain size composition change after feldspathic sandstone and aeolian sandy soil compounding. - Science of Soil and Water Conservation 13: 44-49.

[23] Zhu, D., Han, J., Wang, H. (2017): The remediation method of sandy land in the feldspathic sandstone area-a review. - Carpathian Journal of Earth and Environmental Sciences 12: 49-60. 